\title{
Personality traits and emotion regulation: A targeted review and recommendations
}

DOI:

10.1037/emo0000644

\section{Document Version}

Accepted author manuscript

Link to publication record in Manchester Research Explorer

\section{Citation for published version (APA):}

Hughes, D. J., Kratsiotis, I., Niven, K., \& Holman, D. (2020). Personality traits and emotion regulation: A targeted review and recommendations. Emotion. https://doi.org/10.1037/emo0000644

\section{Published in:}

Emotion

\section{Citing this paper}

Please note that where the full-text provided on Manchester Research Explorer is the Author Accepted Manuscript or Proof version this may differ from the final Published version. If citing, it is advised that you check and use the publisher's definitive version.

\section{General rights}

Copyright and moral rights for the publications made accessible in the Research Explorer are retained by the authors and/or other copyright owners and it is a condition of accessing publications that users recognise and abide by the legal requirements associated with these rights.

\section{Takedown policy}

If you believe that this document breaches copyright please refer to the University of Manchester's Takedown Procedures [http://man.ac.uk/04Y6Bo] or contact uml.scholarlycommunications@manchester.ac.uk providing relevant details, so we can investigate your claim.

\section{OPEN ACCESS}


Running Head: PERSONALITY AND EMOTION REGULATION

Personality traits and emotion regulation: A targeted review and recommendations

David J. Hughes, Ioannis Kratsiotis, Karen Niven, \& David Holman

Alliance Manchester Business School

In Press: Emotion special issue on emotion regulation edited by Kateri McCrae and James Gross

Correspondence concerning this article should be addressed to: david.hughes4@manchester.ac.uk 


\begin{abstract}
Where do individual differences in emotion regulation come from? This review examines theoretical and empirical evidence describing the role that personality traits play in shaping individuals' intrapersonal and interpersonal regulation styles. We define and delineate personality traits and emotion regulation and summarize empirical relations between them. Specifically, we review research on the Big Five personality traits in relation to each stage of Gross' (2015) extended process model of emotion regulation. In doing so, we document evidence concerning the relationships between personality traits and three key stages of emotion regulation, namely, identification (i.e., choosing which emotions to regulate), selection (i.e., choosing a broad regulatory approach), and implementation (i.e., adopting specific regulatory tactics). Finally, we make recommendations for future research that we hope will guide researchers in building a systematic understanding of how personality traits shape intrapersonal and interpersonal emotion regulation.
\end{abstract}

Keywords: Personality, Emotion Regulation, Goals, Motives 


\section{Personality traits and emotion regulation: A targeted review and recommendations}

In this review, we summarize research concerning the relationship between personality traits and emotion regulation processes. First, we define and delineate personality traits and emotion regulation. Second, we outline Gross' (2015) extended process model of emotion regulation, which we use to structure our review. Third, we summarize empirical relations between personality traits and emotion regulation. Finally, we make recommendations to guide researchers in building a systematic understanding of relations between personality traits and efforts to regulate one's own and others' emotions.

\section{Defining and distinguishing personality and emotion regulation}

Personality traits describe an individual's relatively stable patterns of thinking, feeling, and behaving (DeYoung, 2015). Here, we focus upon the most widely researched personality trait taxonomy, the Big Five. As depicted in Figure 1, personality traits are hierarchically structured, with the Big Five - Neuroticism, Extraversion, Openness-toexperience, Agreeableness, and Conscientiousness - considered broad domains that encompass numerous aspects which in turn contain numerous facets (DeYoung, Quilty, \& Peterson, 2007).

\section{[Insert Figure 1]}

Personality trait inventories describe observed patterns of behavior, with a person scored as extraverted, for example, because they 'talk a lot' and 'enjoy parties'. However, according to Cybernetic Big Five Theory (CB5T), personality traits have a secondary meaning that renders them causal entities. Although inventories assess behavior, personality traits also refer to specific cybernetic mechanisms or psychological processes (e.g., goals, mental representations, and strategies), developed in response to evolutionary pressures, that are responsible for generating behavior (DeYoung, 2015). Consequently, traits tend to manifest as characteristic behavioral patterns in response to certain stimuli. That is, a person 
is not extraverted because they talk a lot but because their underlying psychological processes (e.g., goals, mental representations) are such that when faced with certain stimuli (e.g., other people) they predispose certain behavioral patterns that we label 'extraverted'.

Similarly, emotion regulation also describes a cybernetic system. Specifically, emotion regulation refers to the goal-directed processes through which individuals attempt to elicit, change, or maintain emotional states (Gross, 1998; 2015; Niven, 2017). Early work viewed emotion regulation as a within-person process that involved regulating positive and negative emotions (Gross, 1998). However, researchers now recognize the social nature of emotion regulation, which can also involve attempts to influence the emotions of others (Gross, 2015; Niven, 2017).

Because personality and emotion regulation both describe cybernetic processes, they can be considered nested. That is, personality provides a broad framework for all cybernetic mechanisms (e.g., goals, mental representations) and emotion regulation refers to the subset specifically related to the processes of changing emotional states. However, the two are not synonymous. Some personality traits are predominantly cognitive or behavioral in nature (e.g., facets of fantasy, orderliness) and, as discussed next, empirical associations between personality traits and emotion regulation are meaningful but moderate in magnitude (Barańczuk, 2019). Additionally, the two explain unique variance in different domains of affective experiences. For example, Schindler \& Querengässer (2019) found that trait neuroticism predicted susceptibility to experience sadness whereas emotion regulation strategies were unrelated to sadness susceptibility but explained mood repair. Thus, personality and emotion regulation are related but distinct and both contribute to providing a comprehensive description of human affective experience (John \& Gross, 2004). Indeed, theoretical accounts, such as the Integrated Model of Affect-related Individual Differences (IMAID; Hughes \& Evans, 2018) argue that relevant cognitive abilities are associated with 
regulation effectiveness (e.g., those high in ability-based emotional intelligence regulate sooner and use more adaptive strategies; Peña-Sarrionandia et al., 2015) and personality traits account for differences in regulatory style. Thus, the IMAID is an integrated mediation model that posits emotion regulation as one mechanism through which people achieve personalityrelated goals.

\section{The extended process model of emotion regulation}

Perhaps the most comprehensive model of emotion regulation is the extended process model (Gross, 2015). This model has three stages (each containing a perception, valuation, and action element) representing the decisions that determine whether and how regulation will occur. In addition, the model describes higher-level monitoring processes that assess regulatory success.

Stage 1: Identification is concerned with identifying emotions that require regulation. At this stage, a person perceives some element of their situation (an impending exam), makes a value judgement of the element (because I am underprepared, I feel anxious), and then specifies an action goal (reduce anxiety).

Stage 2: Selection is concerned with choosing a regulatory strategy. At this stage, the individual makes a value judgement on how best to achieve the action goal (reduce anxiety) by regulating in one of five broad ways: (i) choosing to engage with or avoid situations (situation selection), (ii) modifying situations (situation modification), (iii) directing attention within situations (attentional deployment), (iv) attributing a meaning to situations (cognitive change), and (v) changing one's physiological and/or psychological response (response modulation). Finally, the individual specifies an action goal to regulate in the chosen way. In our example, the individual might decide that they cannot avoid the situation and instead choose to modify it. 
Stage 3: Implementation is concerned with attempts to enact the regulation in a situation-appropriate manner. Here, the individual perceives the regulatory goal (situation modification), makes a value judgement regarding the specific tactics to employ (e.g., revise using core textbook), and finally, enacts the behavior/cognition.

\section{Why and how does personality shape emotion regulation?}

In this section, we review evidence of the relationships between personality and the perceptions, value-judgements, and goals/actions within the identification, selection, and implementation stages of the emotion regulation process.

\subsection{Personality and Identification}

Research from numerous fields demonstrates that personality traits are associated with the perception (detecting an emotion) and valuation (determining whether an emotion warrants regulation) steps of the identification stage (Carver \& Connor-Smith, 2010; Schindler \& Querengässer, 2019). For example, those high in neuroticism are particularly sensitive to negative affect and try to reduce it immediately (Carver \& Connor-Smith, 2010) and those high in agreeableness have a heightened sensitivity to others' emotions (Suls, Martin, \& David, 1998). Further, and in accordance with CB5T and the IMAID, personality traits shape "the defining feature of emotion regulation [namely] the activation of a goal to influence the emotion trajectory" (Gross, 2015, p. 5). A handful of empirical studies demonstrate that personality traits predict desired affective state (DAS) or how people want to feel (or want others to feel) after regulation (Augustine, Hemenover, Larsen, \& Shulman, 2010; Eldesouky \& English, 2018). For example, Tamir (2005; 2009) found that before taking a test, participants high in neuroticism wanted to increase their feelings of worry, whereas participants high in extraversion wanted to increase their happiness. It might seem odd that anyone would wish to increase negative affect, and fully explaining this effect without personality would be challenging. However, the extraverted and neurotic participants 
display trait-concordant DAS because a test represents a performance episode and traitconcordant affect and goals facilitate task performance (Sheldon \& Elliot, 1999). Thus, those high in neuroticism wish to worry pre-test because they are motivated by a fear of failure, and in that moment, the specific goal of avoiding test failure supersedes the general goal of being happy.

Such findings suggest that DAS varies as a function of personality and broad regulatory goals, with a recent study by Eldesouky and English (2018) demonstrated that personality predicts daily occurrence of these broad regulatory goals. For example, agreeableness predicted the adoption of pro-hedonic and pro-social emotion regulation goals (i.e., increase own and others' happiness) whereas neuroticism predicted the adoption of impression-management based goals (i.e., seek others' approval). In sum, research suggests that personality traits influence how people want to feel post-regulation (i.e., DAS) and why they wish to do so (e.g., to please others, to maximize performance).

\subsection{Personality and Selection}

Once a DAS and regulatory goal have been set, the individual chooses a broad regulatory strategy (e.g., situation modification) to facilitate goal-attainment. Emotion regulation questionnaires typically ask participants about their use of broad strategies, so most personality and emotion regulation research sits within the selection stage. The number of papers in this area allows us to review the use of intrapersonal and interpersonal emotion regulation strategies.

\subsubsection{Personality and intrapersonal regulation strategies}

Although not the primary focus of most studies, empirical associations between the Big Five personality traits and intrapersonal emotion regulation strategy use are numerous. A recent meta-analysis of 132 studies (Barańczuk, 2019) revealed trait-consistent associations between personality traits and eight emotion regulation strategies (See Table 1). For example, 
conscientiousness shares its largest correlation with problem-solving (i.e., regulating emotions by modifying or eliminating stressors, e.g., planning) and openness shares its largest associations with thought-based strategies, namely, rumination (i.e., repetitive focus on stressors) and reappraisal (i.e., generating positive interpretations of a situation). The results also convey the regulatory profiles associated with certain traits. For example, those high on neuroticism use situation selection to avoid threatening scenarios but when in such scenarios they do not problem solve or reappraise, instead tending to ruminate before suppressing unpleasant feelings. In contrast, extraverts are typically proactive, regulating their emotions by modifying rather than avoiding situations, by directing their attention away from worry, and by accepting and reappraising situations before expressing their emotional state. That neurotic individuals frequently suppress their emotions and rarely reappraise, whereas extraverts commonly reappraise and rarely suppress is a robust effect that replicates across age groups, study designs (e.g., cross-sectional, longitudinal, experimental), and countries from multiple continents (Gresham \& Gullone, 2012; Gross \& John, 2003; Haga, Kraft, \& Corby, 2009; Schindler \& Querengässer, 2019; Wang, Shi, \& Li, 2009).

\section{[Insert Table 1]}

Some intrapersonal emotion regulation strategies are typically considered adaptive because their mastery and implementation is associated with greater wellbeing and improved performance across numerous domains (Gross, 2015; McRae, Jacobs, Ray, John, \& Gross, 2012; Southward, Altenburger, Moss, Cregg, \& Cheavens, 2018). Generally, those high on extraversion and conscientiousness - and to a lesser extent agreeableness and openness - use adaptive strategies more often (Ng \& Diener, 2009; Southward et al., 2018). However, those high in openness face some regulatory difficulties because they tend to ruminate (Amiri \& 
Navab, 2018) and those high in neuroticism use maladaptive strategies, lack persistence in their regulatory efforts, and try many strategies when not receiving immediate gains (Southward et al., 2018), which results in less time repairing negative moods or savoring positive moods (Amiri \& Navab, 2018).

\subsubsection{Personality and interpersonal regulation strategies}

Studies of personality and interpersonal emotion regulation are rare and typically focus on how personality traits relate to improving or worsening others' affect. Only agreeableness and extraversion, the most interpersonally oriented Big Five traits, have been studied frequently enough to make general conclusions. Results, using three different interpersonal regulation scales, reveal a relatively consistent picture. Extraverts use proactive strategies (e.g., situation modification, cognitive change; López-Pérez, Morillo, \& Wilson, 2017) in order to improve others' affect (Austin, Saklofske, Smith, \& Tohver, 2014; Niven, Totterdell, Stride, \& Holman, 2011) but are perhaps not averse to also worsening others' affect (Austin \& O’Donnell, 2013). In contrast, agreeable individuals try to avoid worsening others' affect more so than trying to improve it (Austin et al., 2014; López-Pérez et al., 2017; Niven et al., 2011). These studies suggest extraverts are socially dominant, intervene earlier in the process, and are perhaps prepared to 'offend' or worsen others' mood in the short term by engaging in more challenging regulation processes (e.g., reappraisal). In contrast, agreeable individuals choose strategies that enable them to avoid conflict or upsetting others (Suls et al., 1998).

\subsection{Personality and Implementation}

In the implementation stage, individuals enact the selected regulatory strategy using specific cognitive and behavioral tactics. Currently, there is a complete absence of research exploring the relationships between personality traits and specific tactics, but given the associations between personality traits and other aspects of the regulatory process it seems 
likely that personality traits will also be associated with specific implementation tactics (Hughes \& Evans, 2018). For example, because individuals high in neuroticism are avoidance motivated (i.e., want to avoid failure and see many situations as threats) and tend to impression-manage, they might choose to avoid attending a friend's party by using an excuse (e.g., busy with work), to appear passive whilst avoiding offending the friend.

When examining relations between personality traits and implementation tactics, future research might benefit from examining personality facets (Austin \& Vahle, 2016; Hughes \& Evans, 2016; 2018). Whereas the Big Five are broad and contain numerous aspects of personality (DeYoung et al., 2007), facets are unidimensional units of personality (see Figure 1) that often provide more nuanced predictions of behavior (Hughes \& Batey, 2017). For example, two facets of extraversion are excitement-seeking (i.e., enjoyment of novel and intense experiences) and gregariousness (i.e., sociability). When seeking to up-regulate positive emotions at a 'boring' party those high in excitement-seeking might choose to drink and behave recklessly, whereas those high in gregariousness might talk with as many people as possible. Similarly, a conscientious student high in orderliness (i.e., desire for organization and symmetry) might choose to down-regulate negative emotions when studying by cleaning their home, whereas a student high in achievement striving (i.e., goal driven) might do so by working harder.

\section{Future directions}

This review indicates that studying personality traits can improve our understanding of how and why individual differences in emotion regulation arise. Our most prominent call for future research is to continue this integration using theoretical frameworks such as the extended process model (Gross, 2015) and the IMAID (Hughes \& Evans, 2018). In addition, we identified a number of research gaps: 
1. Research has predominantly studied personality-driven differences in how people regulate (i.e., regulation strategies) with less known about personality-driven differences in why people regulate (i.e., regulatory goals/motives, Niven, 2015; Tamir, 2016). What research there is (e.g., Eldesouky \& English, 2018) suggests that further work will prove fruitful in helping to explain individual differences in emotion regulation.

2. Research has predominantly examined personality in relation to a limited range of emotional regulation strategies (e.g., avoidance, reappraisal, suppression) and completely neglected relations between personality and implementation tactics.

3. Future work might benefit by adopting a person-centric, instead of a variable-centric, approach because individuals may have emotion regulatory styles that arise as a function of personality and vary in effectiveness (Gabriel, Daniels, Diefendorff, \& Greguras, 2015). Similarly, situation-centric approaches would help establish whether individuals use different emotion regulation strategies across situations and help to build a more dynamic and nuanced picture of strategy/tactic use.

4. Greater nuance should be considered when assessing personality. The Big Five subsume numerous narrower facets (see Figure 1), that often provide greater realworld prediction (Hughes, \& Batey, 2017). Perhaps Big Five level traits will be better suited to examining higher-level phenomena (e.g., emotion regulation goals), whereas facet-level traits might be better suited to examining lower-level phenomena such as selection and implementation (Hughes \& Evans, 2018).

5. Similarly, trait taxonomies such as the 'dark triad', which describe socially aversive traits, might provide useful insight. A few studies show that those high in dark traits seek to worsen others' emotions, use inauthentic emotional displays (Austin et al., 
2014; Austin \& Vahle, 2016), and face regulatory difficulties due to failed impulse control (Amiri \& Navab, 2018).

\section{Recommendations for Additional Reading}

Eldesouky, L., \& English, T. (2018). Individual differences in emotion regulation goals: Does personality predict the reasons why people regulate their emotions? Journal of Personality, 1-18.

This two-study paper demonstrates that the Big Five systematically predict the emotion regulation goals that people typically pursue. This evidence demonstrates that personality can helps us to understand why people engage in certain forms of emotion regulation.

John, O. P., \& Gross, J. J. (2004). Healthy and unhealthy emotion regulation: Personality processes, individual differences, and life span development. Journal of personality, 72(6), 1301-1334.

A seminal review that demonstrates why individual differences in emotion regulation matter; because patterns of regulation are associated with many markers of health, social functioning, and well-being. It goes on to discuss evidence pertaining personality and a number of other important factors that might give rise to individual differences in emotion regulation.

Hughes, D. J., \& Evans, T. R. (2018). Putting 'emotional intelligences' in their place: Introducing the integrated model of affect-related individual differences. Frontiers in Psychology, 9, 2155.

The Integrated Model of Affect-related Individual Differences (IMAID) argues that cognitive ability and personality traits interrelate and coalesce to influence stylistic patterns of emotion regulation.

Schindler, S., \& Querengässer, J. (2019). Coping with sadness: How personality and emotion regulation strategies differentially predict the experience of induced emotions.

Personality and Individual Differences, 136, 90-95.

This repeated-measures experimental study demonstrates that personality and emotion regulation explain distinct elements of emotional experience. The results showed a number of effects, including bi-directional effects whereby personality influenced sadness susceptibility and experiencing sadness influenced expressed personality. In contrast emotion regulation strategies did not correlate with sadness susceptibility but influenced mood repair.

Tamir, M. (2005). Don't worry, be happy? Neuroticism, trait-consistent affect regulation, and performance. Journal of Personality and Social Psychology, 89, 449-461.

This multi-study paper reports on a number of rigorous and thoughtful experiments. The results demonstrate the complex yet theoretically consistent relationships between personality, emotion regulation goals, situational pressures, and regulatory strategy. 


\section{References}

Amiri, S., \& Navab, A. G. (2018). The association between the adaptive/maladaptive personality dimensions and emotional regulation. Neuropsychiatria $i$ Neuropsychologia, 13(1), 1-8.

Augustine, A. A., Hemenover, S. H., Larsen, R. J., \& Shulman, T. E. (2010). Composition and consistency of the desired affective state: The role of personality and motivation. Motivation and Emotion, 34(2), 133-143.

Austin, E. J., Saklofske, D. H., Smith, M., \& Tohver, G. (2014). Associations of the managing the emotions of others (MEOS) scale with personality, the Dark Triad and trait EI. Personality and Individual Differences, 65, 8-13.

Austin, E. J., \& Vahle, N. (2016). Associations of the Managing the Emotions of Others Scale (MEOS) with HEXACO personality and with trait emotional intelligence at the factor and facet level. Personality and Individual Differences, 94, 348-353.

Barańczuk, U. (2019). The five factor model of personality and emotion regulation: A metaanalysis. Personality and Individual Differences, 139, 217-227.

Carver, C. S., \& Connor-Smith, J. (2010). Personality and coping. Annual review of psychology, 61, 679-704.

DeYoung, C. G. (2015). Cybernetic Big Five Theory. Journal of Research in Personality, 56, 33-58.

DeYoung, C. G., Quilty, L. C., \& Peterson, J. B. (2007). Between facets and domains: 10 aspects of the Big Five. Journal of Personality and Social Psychology, 93, 880-896.

Eldesouky, L., \& English, T. (2018). Individual differences in emotion regulation goals: Does personality predict the reasons why people regulate their emotions? Journal of Personality, 1-18.

Frederickx, S., \& Hofmans, J. (2014). The role of personality in the initiation of communication situations. Journal of Individual Differences, 35(1), 30-37. 
Gabriel, A. S., Daniels, M. A., Diefendorff, J. M., \& Greguras, G. J. (2015). Emotional labor actors: A latent profile analysis of emotional labor strategies. Journal of Applied Psychology, 100, 863-879.

Gresham, D., \& Gullone, E. (2012). Emotion regulation strategy use in children and adolescents: The explanatory roles of personality and attachment. Personality and Individual Differences, 52, 616-621.

Gross, J. J. (1998). The emerging field of emotion regulation: An integrative review. Review of General Psychology, 2, 271-299.

Gross, J. J. (2015). Emotion regulation: Current status and future prospects. Psychological Inquiry, 26, 1-26.

Gross, J. J., \& John, O. P. (2003). Individual differences in two emotion regulation processes: Implications for affect, relationships, and well-being. Journal of Personality and Social Psychology, 85(2), 348-362.

Haga, S. M., Kraft, P., \& Corby, E. K. (2009). Emotion regulation: Antecedents and wellbeing outcomes of cognitive reappraisal and expressive suppression in cross-cultural samples. Journal of Happiness Studies, 10, 271-291.

Hughes, D. J., \& Batey, M. (2017). Using personality questionnaires for selection, in The Wiley Blackwell Handbook of the Psychology of Recruitment, Selection \& Retention, eds H. Goldstein, E. Pulakos, J. Passmore, and C. Semedo (Chichester:Wiley Blackwell), 151-181.

Hughes, D. J., \& Evans, T. R. (2016). Comment: trait EI moderates the relationship between ability EI and emotion regulation. Emotion Review 8, 331-332. doi:

$10.1177 / 1754073916650502$ 
Hughes, D. J., \& Evans, T. R. (2018). Putting 'emotional intelligences' in their place: Introducing the integrated model of affect-related individual differences. Frontiers in Psychololgy, 9, 2155. doi:10.3389/fpsyg.2018.02155

Komulainen, E., Meskanen, K., Lipsanen, J., Lahti, J. M., Jylha, P., Melartin, T., Wichers, M., Isometsa, E., \& Ekelund, J. (2014) The Effect of Personality on Daily Life Emotional Processes. PLoS ONE 9(10), 1-9.

López-Pérez, B., Morillo, D., \& Wilson, E. (2017). Development and validation of the Interpersonal Affect Improvement Strategies Questionnaire. European Journal of Psychological Assessment. Advance online publication. http://dx.doi.org/10.1027/1015-5759/a000394

McRae, K., Jacobs, S. E., Ray, R. D., John, O. P., \& Gross, J. J. (2012). Individual differences in reappraisal ability: Links to reappraisal frequency, well-being, and cognitive control. Journal of Research in Personality, 46(1), 2-7.

Ng, W., \& Diener, E. (2009). Personality differences in emotions: Does emotion regulation play a role? Journal of Individual Differences, 30(2), 100-106.

Niven, K. (2015). Why do people engage in interpersonal emotion regulation at work? Organizational Psychology Review, 6(4), 305-323.

Niven, K. (2017). The four key characteristics of interpersonal emotion regulation. Current Opinion in Psychology, 17, 89-93.

Niven, K., Totterdell, P., Stride, C. B., \& Holman, D. (2011). Emotion regulation of others and self (EROS): The development and validation of a new individual difference measure. Current Psychology, 30, 53-73.

Peña-Sarrionandia, A., Mikolajczak, M., \& Gross, J. J. (2015). Integrating emotion regulation and emotional intelligence traditions: A meta-analysis. Frontiers Psychology, 6, 160. doi:10.3389/fpsyg.2015.00160 
Schindler, S., \& Querengässer, J. (2019). Coping with sadness: How personality and emotion regulation strategies differentially predict the experience of induced emotions. Personality and Individual Differences, 136, 90-95.

Sheldon, K., \& Elliot, A. J. (1999). Goal striving, need satisfaction, and longitudinal wellbeing: The self-concordance model. Journal of Personality and Social Psychology, 76(3), 482-97.

Southward, M. W., Altenburger, E. M., Moss, S. A., Cregg, D. R., \& Cheavens, J. S. (2018). Flexible, yet firm: A model of healthy emotion regulation. Journal of Social and Clinical Psychology, 37(4), 231-251.

Suls, J., Martin, R., \& David, J. P. (1998). Person-environment fit and its limits: Agreeableness, neuroticism, and emotional reactivity to interpersonal conflict. Personality and Social Psychology Bulletin, 24(1), 88-98.

Tamir, M. (2005). Don't worry, be happy? Neuroticism, trait-consistent affect regulation, and performance. Journal of Personality and Social Psychology, 89, 449-461.

Tamir, M. (2009). Differential preferences for happiness; Extraversion and trait-consistent emotion regulation. Journal of Personality, 77, 447-470.

Tamir, M. (2016). Why do people regulate their emotions? A taxonomy of motives in emotion regulation. Personality and Social Psychology Review, 20, 199-222.

Wang, L., Shi, X., \& Li, H. (2009). Neuroticism, extraversion, emotion regulation, negative affect and positive affect: The mediating roles of reappraisal and suppression. Social Behavior and Personality, 37(2), 193-194. 
Table 1

Correlations between personality traits and use of intrapersonal emotion regulation strategies derived from Barańczuk (2019)

\section{Emotion regulation strategies}

Neuroticism $\quad$ Extraversion

\section{Personality traits}

Situation Selection

Avoidance

$$
.31 * *
$$

$-.17 * *$

$.47 * *$

$-.34 * *$

$-.19 * *$

.03

$.21^{* *}$

.04

Openness

Response Modulation

Suppression of thoughts

Suppression of emotion
Agreeableness

Conscientiousness

expression

Note: $* \mathrm{p} \leq .01 . * * \mathrm{p} \leq .001$
$-.10^{*}$

$.21^{* *}$

$.18 * *$

$-.20 * *$

$.15^{* *}$

$.22 * *$

$.13 * *$

$.22 * *$

$.12 *$

$.20 * *$

.02

.02

$.05^{*}$

$-.12 *$

$-.13^{*}$

$12 * *$

$.29 * *$

$19 * *$

$15^{* * *}$

$.19 * *$

$18 * *$

$.11 *$

1** $\quad .02$

$-.37 * *$

$-.12 * *$

$-.15^{* *}$

$-.08$ 
Big Five Domains

Ten Aspects

Example facets. Total number is large, estimates range from $30-100$

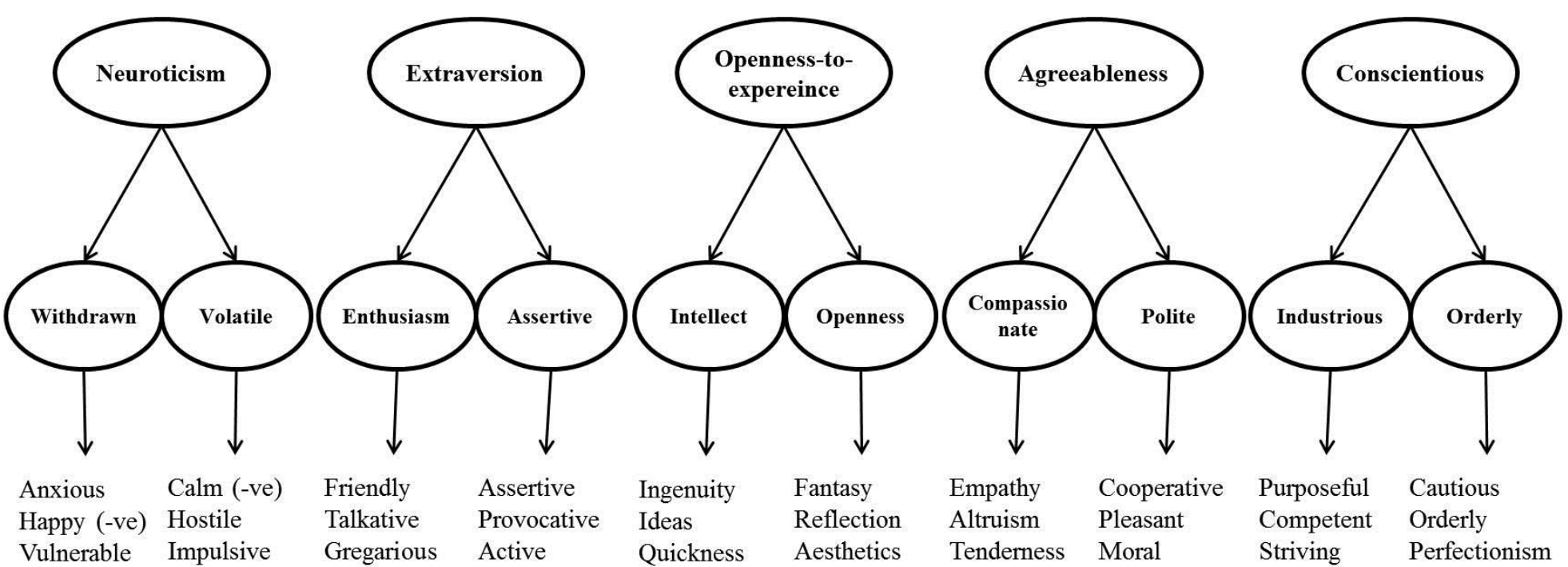

Figure 1. Illustrative model of the Big Five Domains, the ten Big Five Aspects, and example facets 